\title{
Post-surgical recovery and time-of-day mask potentiated responses of ACTH to repeated moderate hemorrhage in conscious rats
}

\author{
M P Lilly, R O Jones, D J Putney and D E Carlson \\ Department of Surgery, University of Maryland Baltimore, School of Medicine, Baltimore, Maryland, USA \\ (Requests for offprints should be addressed to M P Lilly, Department of Surgery, University of Maryland Hospital, 22 South Greene Street, Baltimore, \\ Maryland 21201-1595, USA; Email: mlilly@smail.umaryland.edu)
}

\begin{abstract}
We determined how changes in the responsiveness of the hypothalamo-pituitary-adrenal (HPA) system that accompany experimentation affect facilitation of HPA responses to hemorrhage. Hemorrhage $(10 \mathrm{ml} / \mathrm{kg}$ over $3 \mathrm{~min})$ was performed in conscious, chronically prepared rats. Blood was sampled over $1 \mathrm{~h}$ followed by reinfusion of shed blood. Hemorrhage was performed either once or twice separated by $24 \mathrm{~h}$ in different groups of animals. To test the effect of the circadian variation in responsiveness, rats were hemorrhaged on days 4 and 5 after surgery either in the morning (AM) or in the afternoon (PM). The response of $\mathrm{ACTH}$ to hemorrhage on day 4 was greater in the PM than in the AM $(P<0 \cdot 01)$. The ACTH response to the second hemorrhage on day 5 was greater than that to hemorrhage on day 4 only in the AM group $(P<0 \cdot 01)$. Thus, facilitation of ACTH responses by prior hemorrhage was evident only in the AM. To determine the effects of surgical recovery, additional experiments were done in the AM either early (days 3 and 4) or later (days 6 and 7) after
\end{abstract}

surgery. In these experiments, hemorrhage was performed in all rats on days 4 and 7 and either hemorrhage or blood sampling alone was performed on day 3 and 6 . ACTH did not increase in rats with sampling and no hemorrhage. ACTH increased more after an initial hemorrhage on day 3 than on day $6(P<0 \cdot 01)$. ACTH response to hemorrhage on day 4 was greater when preceded by hemorrhage vs sampling on day $3(P<0 \cdot 01)$. ACTH response to hemorrhage in rats bled twice did not differ on day 3 and day 4 . On day 7 , the response of ACTH in rats that had hemorrhage on day 6 was greater than both their own response on day 6 and the response of a control group with sampling on day $6(P<0 \cdot 01)$. These results demonstrate potentiation of ACTH responses to hemorrhage by an earlier similar hemorrhage, but clearly indicate that enhanced sensitivity of the HPA to hemorrhage either by circadian factors or by surgery can mask this effect.

Journal of Endocrinology (2000) 167, 205-217

\section{Introduction}

The responses of the hypothalamo-pituitary-adrenal (HPA) system to various stressors serve as classic models of responses to injury, and this system has characteristics that lead to important interactions between stressors applied in a temporal sequence. In particular, the responses of the HPA system are sensitive to the recent past history of the subject and manifest either inhibitory or facilitatory effects depending upon experimental conditions (Keller-Wood \& Dallman 1984). Delayed negative feedback from the increase in circulating corticosteroids after an initial stimulus may inhibit the HPA system response to a second stimulus. This mechanism is evident in the neuroendocrine response to repeated episodes of insulin-induced hypoglycemia (Keller-Wood \& Dallman 1984). In contrast, the responses to other stimuli that are readily suppressed by exogenous infusions of corticosteroids in physiological doses are resistant to negative feedback from the endogenous release of steroids by a prior stimulus
(Dallman \& Jones 1973, Gann et al. 1977, Keller-Wood \& Dallman 1984). The initial application of such a stimulus is thought to cause facilitation within various signaling pathways that opposes or possibly bypasses (Dallman \& Yates 1968, Gann \& Cryer 1973, Keller-Wood \& Dallman 1984, Plotsky et al. 1993) the delayed negative feedback signal from the adrenocortical response to the first stimulus. In the case of repeated hemorrhage in dogs (Lilly et al. 1983, 1986, 1989, Lilly 1994) and cats (Thrivikraman et al. 1993), this facilitation is often strong enough that the responses of adrenocorticotropin (ACTH) and corticosteroids to a second episode of modest hypovolemia are significantly greater than those to the first episode.

Rats are frequently used to investigate the central neural mechanisms of integrative responses to stress because our knowledge of the underlying neuroanatomy and neuropharmacology is reasonably complete and precise in this species. Although corticosteroid negative feedback is readily demonstrated in rats (Keller-Wood \& Dallman 
1984), facilitation of the HPA system after repeated stress similar to that seen in other species (Lilly et al. 1983, 1986, 1989, Thrivikraman et al. 1993, Lilly 1994) has not been reported. Rather, the presence of physiological facilitation has been inferred by the failure to show feedback inhibition from the response of corticosterone to the initial stimulus (Dallman \& Jones 1973, Akana et al. 1992, Thrivikraman \& Plotsky 1993), or demonstrated through the use of non-physiological models such as adrenalectomized subjects (Andrés et al. 1999). We hypothesized that in rats external stimuli related to experimental preparation or design result in generalized facilitation of the HPA that masks any further potentiation of this system by a discrete experimental stimulus. In the present study we tested this hypothesis with experiments designed to examine the role of circadian factors and non-specific factors related to surgical preparation. We used an interval of $24 \mathrm{~h}$ between the repeated episodes of hypovolemia to eliminate the influence of the time-of-day on the results and to allow sufficient time for the resolution of corticosteroid negative feedback from the initial stimulus (Keller-Wood \& Dallman 1984). We first compared the repetition of hemorrhage in the morning (AM) when the responsiveness of the system to this stimulus was at its nadir to the repetition of hemorrhage in the afternoon (PM) near the circadian peak. We then examined effects related to the recovery from surgery. The response to a second hemorrhage only increased from that to an initial hemorrhage on the previous day when the stimuli were done in the AM and at least 4 days were allowed for the facilitation of the system by the initial surgery to subside (Lilly \& Gann 1982, Lilly 1994). Thus, our findings define a model to explore the central neural pathways and mechanisms of the modulation of the HPA system during repeated stimulation. Employing this model, we have recently demonstrated the necessity of neural processing in the caudal amygdala for potentiated HPA system responses to repeated hemorrhage (Lilly et al. 2000).

\section{Materials and Methods}

\section{Animals and surgery}

Male Sprague-Dawley rats (Charles River, Wilmington, MA, USA) (body weight $302-480 \mathrm{~g}$ ) were housed in groups of five to eight in a temperature- $\left(18-21^{\circ} \mathrm{C}\right)$ and humidity-controlled, light-cycled (lights on 0700-1900 h) rodent room and allowed food (PMI Feeds, St Louis, MO, USA) and water freely. After 7-10 days of acclimation to the facility, rats were anesthetized with pentobarbital $(50 \mathrm{mg} / \mathrm{kg}$, i.p.) after induction by inhalation of halothane. Femoral arterial and venous catheters were placed by the method of Raff et al. (1983) and Raff \& Fagin (1984) as modified by Darlington et al. (1986) under clean surgical conditions. Catheters (arterial: Dural Plastics, Auburn, New South Wales, Australia; venous: PE-50) were tunneled s.c. to emerge from the dorsal aspect of the neck and passed through a spring. All surgical wounds were treated with lidocaine $\mathrm{HCl}$ (2\%, Astra Pharmaceuticals, Westborough, MA, USA) and bacitracin (Fougera, Melville, NY, USA), and were closed with sutures. After surgery, rats were housed in individual cages in the same rodent room and were not moved from the room until completion of the experiment. The catheters were filled with heparin solution $(1000 \mathrm{U} / \mathrm{ml})$ and sealed. The protective spring was passed through the roof of the cage to allow full mobility of the rat within the cage and to permit repeated sampling of blood without disturbing the animals during the experiments. After full recovery from anesthesia, rats were given free access to food and water. Hormonal responses were measured on two consecutive days a minimum of 3 days after surgery (day of surgery= day 0$)$.

\section{Experiment 1}

The first experiment was designed to determine the influence of the circadian rhythm on the response of ACTH to two hemorrhages, each of $10 \mathrm{ml} / \mathrm{kg}$ in volume, separated by an interval of $24 \mathrm{~h}$. The hemorrhages were done on day 4 and 5 after surgery in two groups of rats. All rats were bled twice via the arterial catheter over $3 \mathrm{~min}$. One group was bled at 0830-0930 h (90 to $150 \mathrm{~min}$ after lights on, AM group) and the other was bled at 1630$1730 \mathrm{~h}$ (PM group). For each hemorrhage, arterial blood $(0.3 \mathrm{ml})$ was sampled at 0 (the first $0.3 \mathrm{ml}$ of the hemorrhage volume), 10, 20, 30 and $60 \mathrm{~min}$. Mean arterial pressure was recorded at the end of hemorrhage and immediately prior to each blood sample using a pressure transducer (Cobe Laboratories, Lakewood, CO, USA) and a blood pressure analyzer (Micro-Med, Inc., Louisville, KY, USA). The arterial catheter was flushed after each sample with heparinized saline solution $(0.3-0.5 \mathrm{ml}, 0.9 \%$ $\mathrm{NaCl}$ with heparin $50 \mathrm{U} / \mathrm{ml}$ ). The blood from the first hemorrhage minus the volume of the control sample $(0.3 \mathrm{ml})$ was anticoagulated with heparin $(10 \mathrm{U} / \mathrm{ml})$ and sample tubes were chilled to $4{ }^{\circ} \mathrm{C}$. After taking the $60 \mathrm{~min}$ sample, this blood was reinfused via the venous catheter. Each rat was administered an additional $3.0 \mathrm{ml}$ sterile saline solution $(0.9 \% \mathrm{NaCl})$ i.v. to compensate for any residual deficit in blood volume. Red blood cells from the samples were not returned to the rat. The volume of red blood cells sampled during this protocol was $\sim 0.7 \mathrm{ml}$ (about $1 \cdot 8-2 \cdot 3 \mathrm{ml} / \mathrm{kg}$ ). Water was withheld during the hemorrhage and sampling protocol. Animals were given free access to water and food at the completion of reinfusion.

\section{Experiment 2}

The results of experiment 1 indicated that facilitated responses of ACTH to the second hemorrhage were seen 
only in the AM group. The second experiment was designed to determine whether the greater response to the second hemorrhage resulted from an effect of the first hemorrhage or from an effect related to recovery from the stress of the preparative surgery (Lilly \& Gann 1982, Raff et al. 1983, Lilly 1994). The treatments are indicated by $S$ for sampling only and $\mathrm{H}$ for hemorrhage and sampling. Rats were studied on two sequential days beginning with either day 3 (groups 3,4-SH and 3,4-HH) or day 6 (groups 6,7-SH and 6,7-HH) after surgery at 0830-0930 h (90 to $150 \mathrm{~min}$ after lights on). On the first day, rats were subjected to either hemorrhage $(10 \mathrm{ml} / \mathrm{kg}$ removed in $3 \mathrm{~min}$ ) and arterial sampling (groups 3,4-HH and 6,7-HH) or to sampling alone (groups 3,4-SH and 6,7-SH). On the second day, all rats were hemorrhaged and sampled as described for experiment 1 . The protocol for the first day differed from that in experiment 1 in that arterial blood $(0.3 \mathrm{ml})$ was only sampled at 0,30 and $60 \mathrm{~min}$, and no hemodynamic variables were measured. On the second day both mean arterial pressure and heart rate were measured before each blood sample. As in experiment 1, blood removed by hemorrhage on the first day minus the volume of the first sample was reinfused via the venous catheter after the $60 \mathrm{~min}$ sample. Each hemorrhaged rat was then administered an additional $3.0 \mathrm{ml}$ sterile saline solution $(0.9 \% \mathrm{NaCl})$ i.v. to compensate for any residual blood volume deficit. Water was withheld during the hemorrhage and sampling protocol. Animals were given free access to water and food at completion of reinfusion.

In both experiments 1 and 2, rats were killed after the 60 min sample on the second experimental day by pentobarbital overdose $(100 \mathrm{mg} / \mathrm{kg}$ i.v.). All experimental procedures in this report conform with Guidelines on the Handling and Training of Laboratory Animals (Universities Federation for Animal Welfare, Wheathampstead, Herts, UK) and were reviewed and approved by the Institutional Animal Care and Use Committee of the University of Maryland, Baltimore.

\section{Assays}

Blood samples were treated with EDTA $(30 \mathrm{mg} / \mathrm{ml})$, and sample tubes were chilled to $4{ }^{\circ} \mathrm{C}$ and centrifuged. The plasma fraction of each sample was frozen at $-80^{\circ} \mathrm{C}$ until the hormones were assayed. Corticosterone was measured by RIA using a commercially available kit without modification (ICN Biochemicals Inc., Costa Mesa, CA, USA). Intra- and interassay coefficients of variation were $7-15 \%$ and $13 \%$ respectively for a rat plasma pool with $86 \mathrm{ng} / \mathrm{ml}$ of corticosterone, and $8-12 \%$ and $11 \%$ respectively for a pool with $260 \mathrm{ng} / \mathrm{ml}$ of the hormone. ACTH was measured by RIA using a commercially available kit (\#24065, Incstar (now DiaSorin), Stillwater, MN, USA) either with or without modification as described by Carlson et al. (1989). Intra- and interassay coefficients of variation for the ACTH RIA were 6-12\% and 19\% respectively for a rat plasma pool with $13 \mathrm{pg} / \mathrm{ml}$ of ACTH, and $3-8 \%$ and $19 \%$ respectively for a pool with $179 \mathrm{pg} / \mathrm{ml}$ of the hormone.

\section{Statistical analysis}

Because these experiments were designed to evaluate the interaction of two isolated stimuli applied $24 \mathrm{~h}$ apart, we only analyzed data from animals with the lowest initial concentrations of plasma corticosterone on both experimental days as explained in Results. Elevated values were taken as evidence of uncontrolled stimuli of unknown origin that could interfere with the interaction of the hypovolemic stimuli that we imposed (Dallman et al. 1987). Data were analyzed by two-factor ANOVA (Winer et al. 1991). For groups studied on the same day the analysis was corrected for repeated measures over time in the same rat. For the comparison of experiments done in the same rats on sequential days, the analysis was corrected both for repeated measures over time on the same day and for repeated treatments in the same rats on sequential days. If significant main treatment effects were found, individual means were compared using the Student-Newman-Keuls method (Winer et al. 1991). When ANOVA was used to test the responses of $\mathrm{ACTH}$, the analysis was done on the logarithms of the raw data since this monotonic transformation improved the homogeneity of variance as judged by the $F_{\max }$ statistic (Winer et al. 1991) and made the distribution of the data more nearly Gaussian. An alpha error of $<0.05$ was accepted for statistical significance. All data are reported as means \pm S.E.M.

\section{Results}

\section{Experiment 1}

Out of the ten rats studied in the AM, the data from the six rats whose average baseline corticosterone was $\leq 100 \mathrm{ng} / \mathrm{ml}$ were analyzed as representative of the rats least affected by uncontrolled stress. As shown in Fig. 1A, the response of ACTH to the second hemorrhage was significantly greater than that to the first hemorrhage from 10 to $60 \mathrm{~min}$ after hemorrhage $(P<0 \cdot 05)$. Despite the difference in the responses of $\mathrm{ACTH}$, the responses of corticosterone on the two days did not differ (Table 1).

In the PM group the responses of ACTH to hemorrhage on the two days did not differ statistically regardless of the control value of ACTH before hemorrhage. Figure $1 \mathrm{~B}$ shows the responses in a group of seven rats with the lowest average baselines $(<150 \mathrm{pg} / \mathrm{ml})$ for the two days. Resting ACTH (0 min) was greater in the PM than in the AM $(P<0 \cdot 05)$. Furthermore the ACTH response to hemorrhage in the PM was greater at 10 through $30 \mathrm{~min}$ than that of the AM group $(P<0 \cdot 01$, in each case; compare Fig. 1A and B). Since we found no evidence of an enhanced response of ACTH to the second hemorrhage in the PM, corticosterone was not measured. 

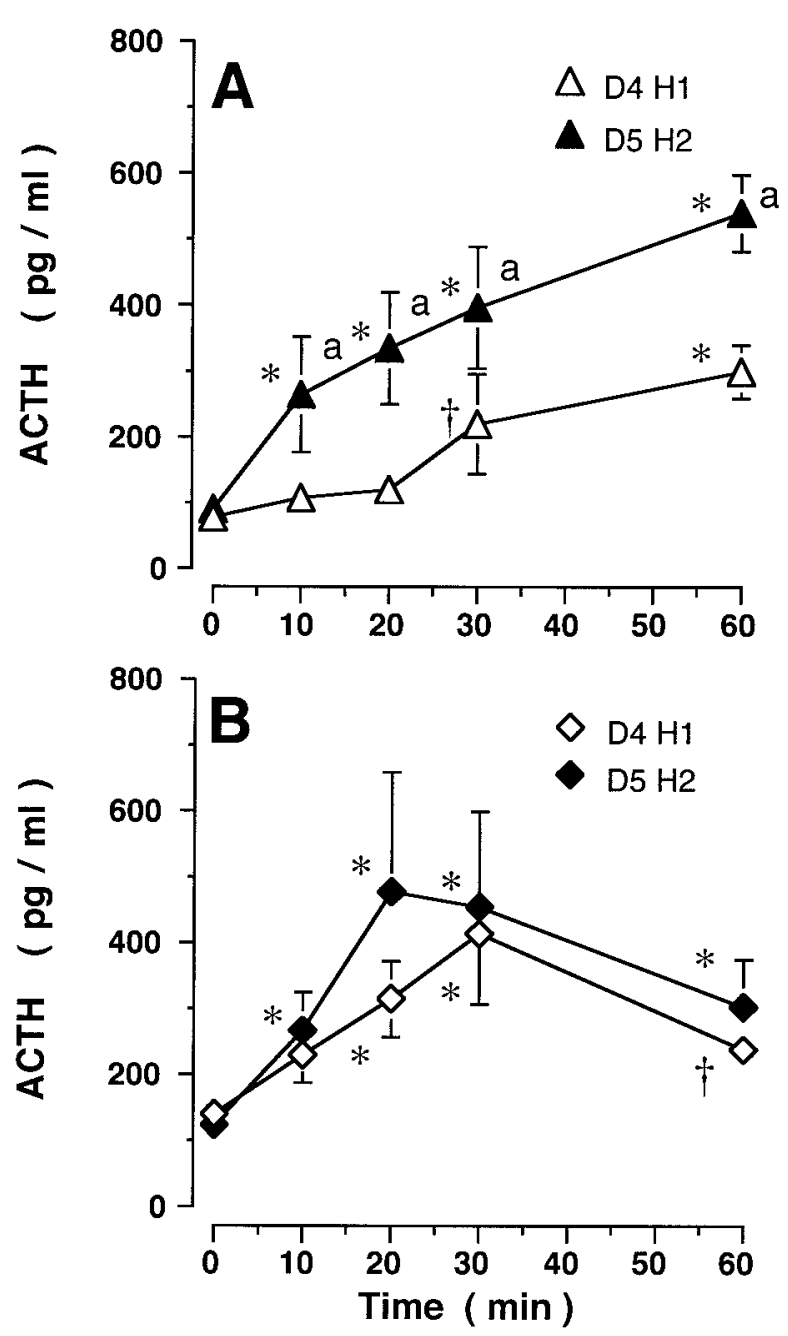

Figure 1 Responses of arterial ACTH in rats that were hemorrhaged $10 \mathrm{ml} / \mathrm{kg}$ on days $4(\mathrm{D} 4 \mathrm{H} 1)$ and $5(\mathrm{D} 5 \mathrm{H} 2)$ after surgery in experiment 1 . Reinfusion after $\mathrm{H} 1$ was at $1 \mathrm{~h}$. Hemorrhages were done either in the AM (A) or in the PM (B) with an interval between hemorrhages of $24 \mathrm{~h} .{ }^{*} P<0.01$ and ${ }^{\dagger} P<0.05$ for change from baseline at time $0 .{ }^{a} P<0.05$ for the difference from $\mathrm{D} 4 \mathrm{H} 1$ at the time of observation.

For both the AM and the PM groups, arterial pressure decreased significantly only after the second hemorrhage (Fig. 2). However, the overall treatment and interaction effects between the first and the second hemorrhage were not significant $(P>0 \cdot 05$, ANOVA). The correlations between the changes in the magnitude of the ACTH response from the first to the second day and the corresponding changes in the magnitude of the hypotension for both the AM $\left(r^{2}=0 \cdot 52, P>0 \cdot 10\right)$ and the PM $\left(r^{2}=0 \cdot 47\right.$, $P>0 \cdot 08)$ groups did not achieve significance.

The results from the small population of rats studied in experiment 1 suggested that potentiated responses of ACTH are best seen in the AM at the nadir of HPA system responsiveness to hemorrhage. However, a possible difference in the hypotension observed after the first and second hemorrhages raised the issue of whether the difference in the HPA responses was the result of hemodynamic effects or changes in the responsiveness of the cardiovascular and HPA systems during the recovery from chronic surgery. The use of the first hemorrhage done on day 4 after surgery as a control for the second hemorrhage done on day 5 did not settle this issue. Experiment 2 was designed to address this concern.

\section{Experiment 2}

We reasoned that the rats in experiment 1 whose control values of corticosterone were $<100 \mathrm{ng} / \mathrm{ml}$ were unlikely to be strongly stressed by uncontrolled factors. However, values of corticosterone in the AM are $\leq 10 \mathrm{ng} / \mathrm{ml}$ in a majority $(\sim 75 \%)$ of undisturbed, uncannulated rats (Dallman et al. 1987). Resting AM values of corticosterone in chronically cannulated rats have been reported in the range of $\sim 25-45 \mathrm{ng} / \mathrm{ml}$ (Fagin et al. 1983). Since the goal of these experiments was to study the responses to hemorrhage of truly resting subjects with minimal corticosteroid feedback, we employed more stringent exclusion criteria for experiment 2. Sufficient rats were studied in experiment 2 that those with resting concentrations of corticosterone $>50 \mathrm{ng} / \mathrm{ml}$ on either of the two experimental days were excluded from analysis. Figure 3 shows frequency histograms of resting corticosterone values of all rats studied on day 3 (panel A) and on day 6 (panel B). Although the distributions of resting corticosterone values were not different on day 3 and day $6(P>0 \cdot 5, t$-test and Kolmogorov-Smirnov test), the median $(37 \cdot 4 \mathrm{ng} / \mathrm{ml}$ day 3 vs $18.7 \mathrm{ng} / \mathrm{ml}$ day 6), and the geometric mean $(23.8 \mathrm{ng} / \mathrm{ml}$ day 3 vs $11.3 \mathrm{ng} / \mathrm{ml}$ day 6$)$ of the distributions were less on day 6. Distributions of resting corticosterone were not different on days 3 vs 4 or days 6 vs 7 . This analysis supports our contention that a greater proportion of rats are in a resting state 6 days after surgery than 3 days after surgery. Our criteria for resting corticosterone in experiment 2 excluded a greater proportion of rats in the day 3,4 groups because of the different distribution of resting values. Response to hemorrhage data were not collected in all excluded rats, but data from rats that received their initial hemorrhage on day 4 after surgery showed evidence that rats excluded by the higher resting corticosterone criteria were subject to uncontrolled stimulation. The average increase of ACTH at 30 and $60 \mathrm{~min}$ in six excluded animals (high corticosterone controls ranged from 53.6 to $91.7 \mathrm{ng} / \mathrm{ml}$ ) was $109 \pm 44.4 \mathrm{pg} / \mathrm{ml}$ compared to only $8 \cdot 8 \pm 2 \cdot 8 \mathrm{pg} / \mathrm{ml}$ in seven rats with values $\leq 50 \mathrm{ng} / \mathrm{ml}$. Both the responses and the variances of the responses in the two groups differed $(P<0 \cdot 01$, in each case).

In the remaining experiments, ACTH was assayed only in rats with resting corticosterone $<50 \mathrm{ng} / \mathrm{ml}$ on both 
Table 1 Response of corticosterone $(\mathrm{ng} / \mathrm{ml})$ to hemorrhages done in the mornings of post-operative days 4 and 5 in the same group of six rats

\begin{tabular}{|c|c|c|c|c|c|}
\hline \multirow{2}{*}{$\begin{array}{l}\text { Post-operative } \\
\text { day }\end{array}$} & \multicolumn{5}{|c|}{ Time after hemorrhage (min) } \\
\hline & 0 & 10 & 20 & 30 & 60 \\
\hline 4 & $50 \cdot 5 \pm 17 \cdot 9$ & $171 \pm 37 \cdot 7^{\dagger}$ & $246 \cdot 5 \pm 27 \cdot 6^{*}$ & $331 \pm 43 \cdot 0^{*}$ & $412 \pm 35 \cdot 8^{*}$ \\
\hline 5 & $31 \cdot 5 \pm 13 \cdot 1$ & $198 \pm 28 \cdot 0^{*}$ & $312 \pm 70 \cdot 1$ * & $280 \pm 54 \cdot 8^{*}$ & $396 \pm 48 \cdot 2^{*}$ \\
\hline
\end{tabular}

${ }^{*} P<0 \cdot 01$ and ${ }^{\dagger} P<0 \cdot 05$ for difference from value at time 0 .

experimental days. In Table 2 and Figs 4 and 5 the four groups in this experiment are designated using numbers for the days of study $(3,4$ or 6,7$)$ and letters indicating the

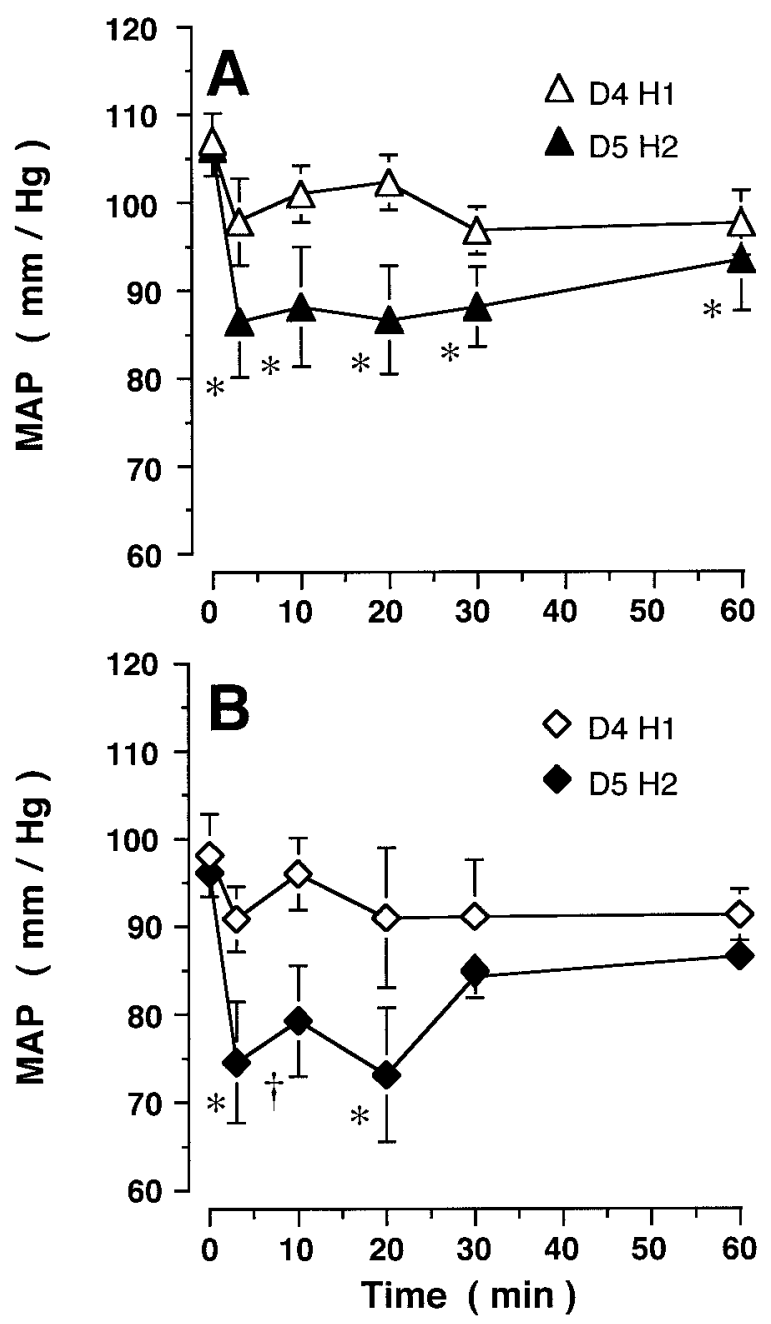

Figure 2 Responses of mean arterial pressure (MAP) in rats that were hemorrhaged $10 \mathrm{ml} / \mathrm{kg}$ on days $4(\mathrm{D} 4 \mathrm{H} 1)$ and $5(\mathrm{D} 5 \mathrm{H} 2)$ after surgery in experiment 1 . Reinfusion after $\mathrm{H} 1$ was at $1 \mathrm{~h}$. Hemorrhages were done either in the AM (A) or in the PM (B) with an interval between hemorrhages of $24 \mathrm{~h}$. Symbols as in Fig. 1. treatments ( $\mathrm{S}$ for sampling only and $\mathrm{H}$ for hemorrhage and sampling). The mean body weight of the group that received sampling only on day $3(3,4-\mathrm{SH})$ was significantly greater than in the other three groups $(432 \pm 17 \mathrm{~g}$ vs $354 \pm 11 \mathrm{~g}(3,4-\mathrm{HH})$ vs $372 \pm 7 \mathrm{~g}(6,7-\mathrm{SH})$ and vs $380 \pm$ $12 \mathrm{~g}(6,7-\mathrm{HH}), P<0 \cdot 001$ each group). Total hemorrhage volume per $\mathrm{kg}$ of body weight on the second day did not differ between groups $(12 \cdot 3 \pm 0 \cdot 1 \mathrm{ml} / \mathrm{kg}(3,4-\mathrm{SH})$ vs $12 \cdot 8 \pm 0 \cdot 1 \mathrm{ml} / \mathrm{kg}(3,4-\mathrm{HH})$ vs $12 \cdot 7 \pm 0 \cdot 1 \mathrm{ml} / \mathrm{kg}(6,7-\mathrm{SH})$

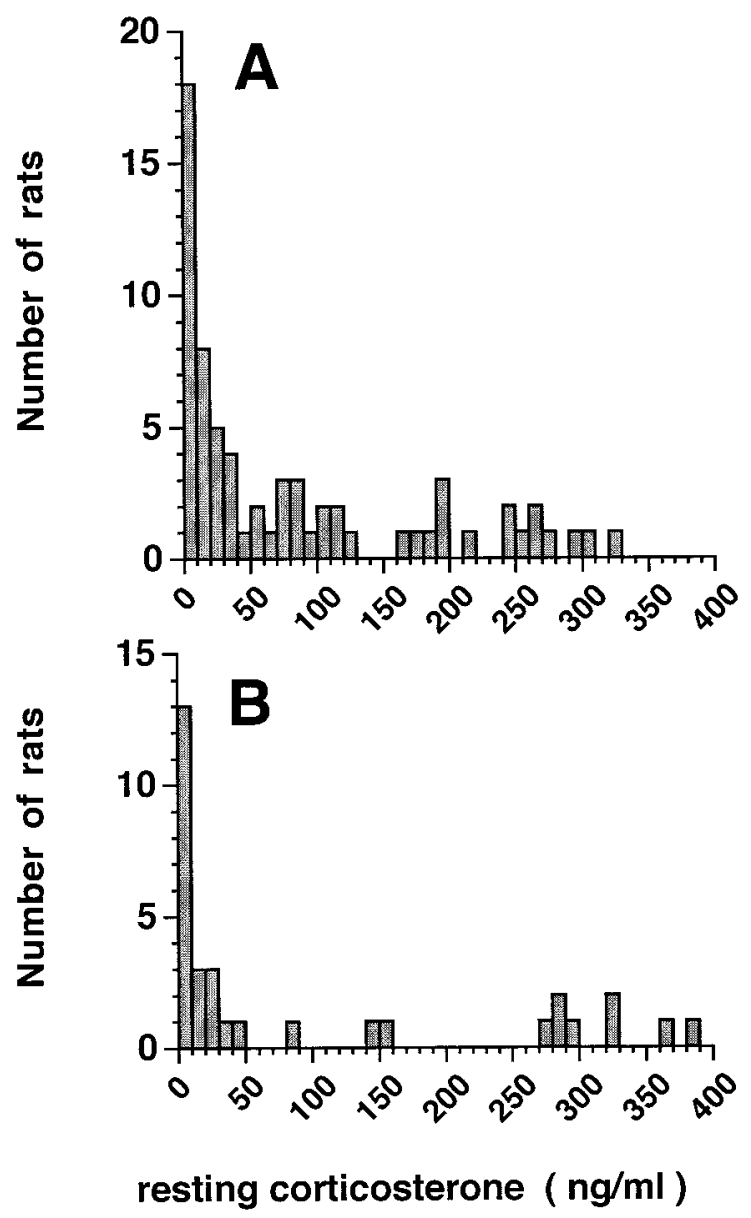

Figure 3 Frequency histograms of resting corticosterone in all rats studied on day $3(A, n=68)$ or day $6(B, n=32)$ of experiment 2 . 


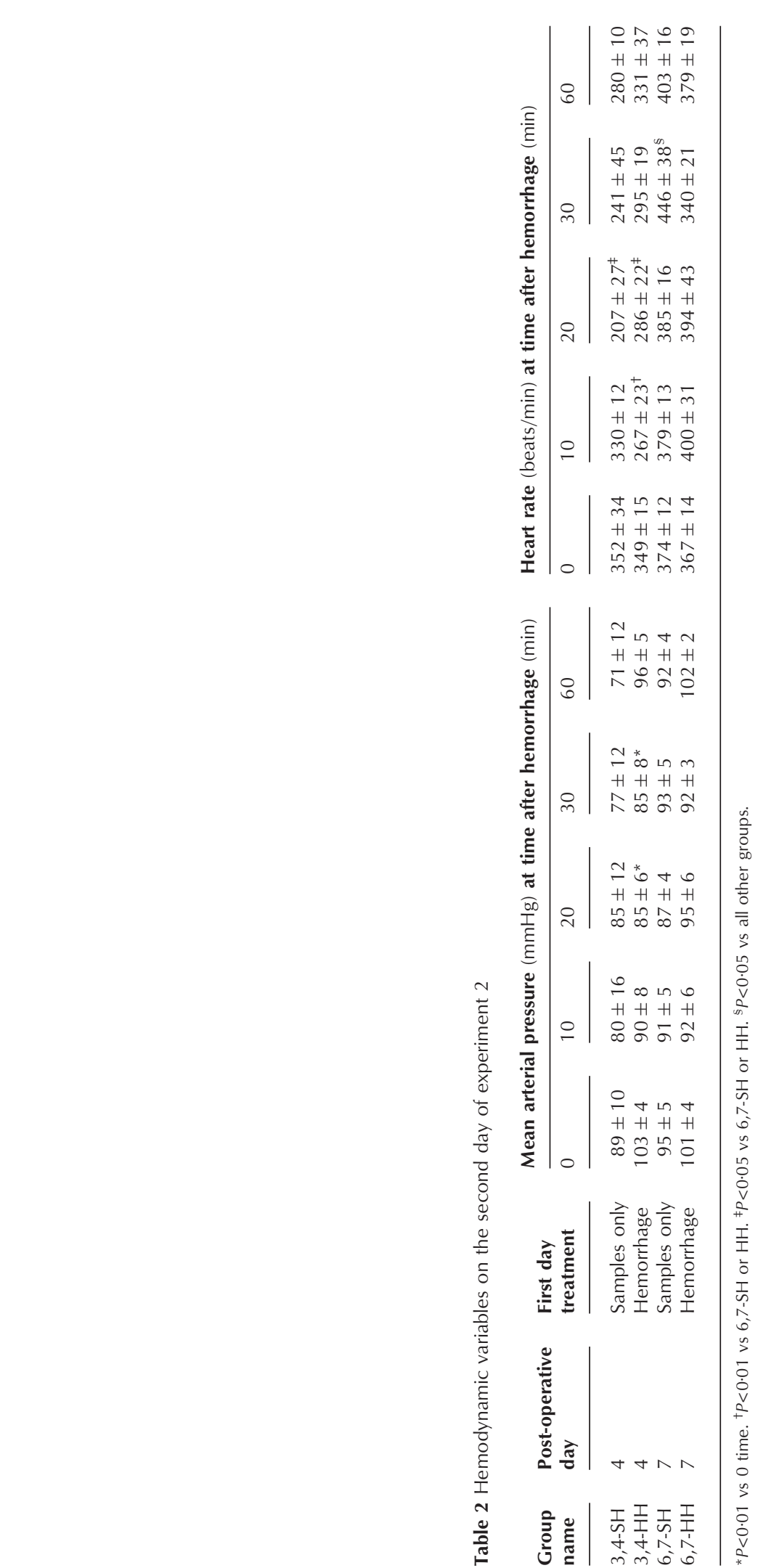




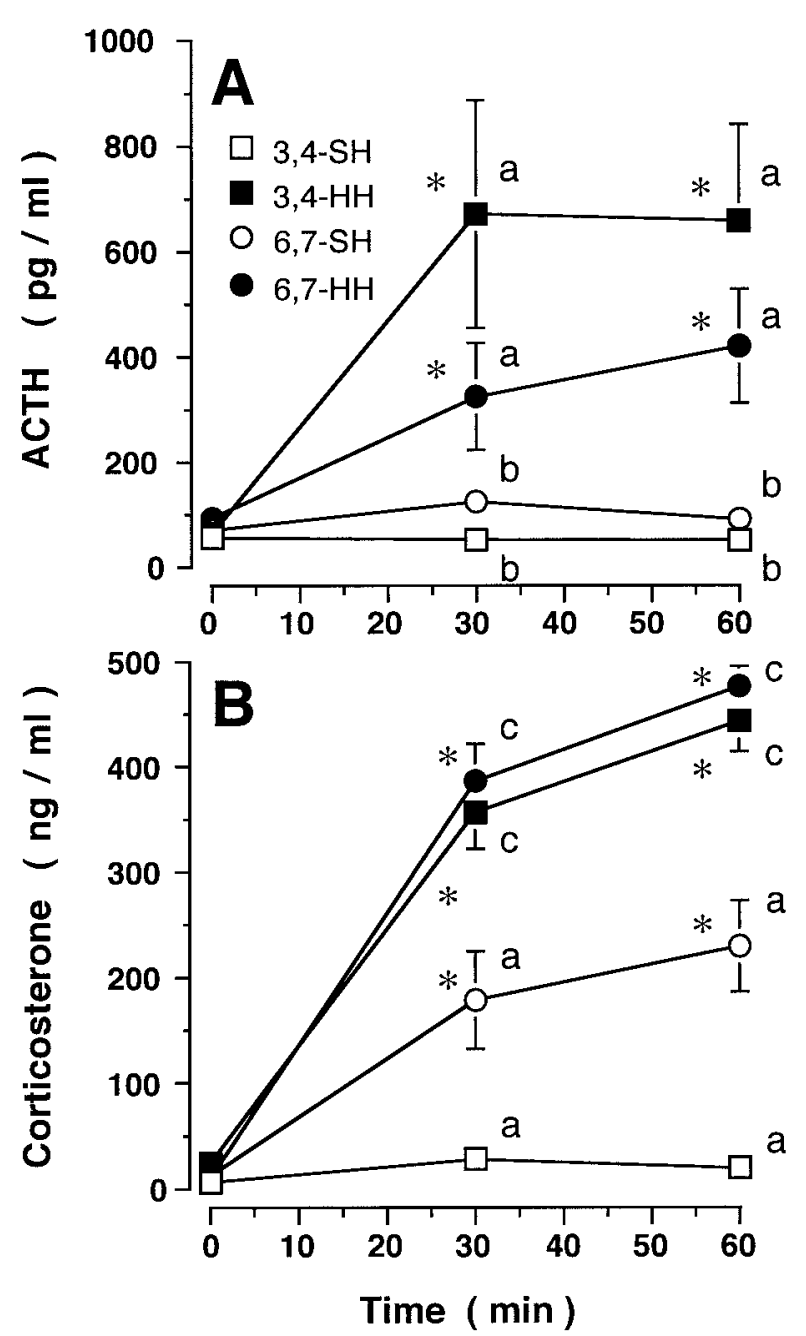

Figure 4 Responses of arterial ACTH (A) and arterial corticosterone (B) on the first day of experiment 2. A first hemorrhage of $10 \mathrm{ml} / \mathrm{kg}$ or sampling alone was done on either day $3(3,4-\mathrm{SH}$ or $3,4-\mathrm{HH})$ or day $6(6,7-\mathrm{SH}$ or $6,7 \mathrm{HH})$ after surgery. ${ }^{*} \mathrm{P}<0 \cdot 01$ for change from baseline at time 0 . Differences significant at the time of observation: ${ }^{a} P<0 \cdot 01$, different from all others. ${ }^{b} P<0 \cdot 01$, different from hemorrhage. ${ }^{c} P<0 \cdot 01$, different from no hemorrhage.

vs $12 \cdot 7 \pm 0 \cdot 1 \mathrm{ml} / \mathrm{kg}(6,7-\mathrm{HH}))$. In the rats that were hemorrhaged twice $(3,4-\mathrm{HH}$ and $6,7-\mathrm{HH})$, the total volume that was removed with hemorrhage and sampling on the second experimental day was slightly but significantly greater than that on the first experimental day because of the additional blood samples taken at 20 and $30 \mathrm{~min}$ on the second day $(11 \cdot 1 \pm 0 \cdot 1 \mathrm{ml} / \mathrm{kg} \mathrm{H} 1$ vs $12 \cdot 8 \pm 0 \cdot 1 \mathrm{ml} / \mathrm{kg} \mathrm{H} 2, P<0 \cdot 01)$.

First day As shown in Fig. 4A, $10 \mathrm{ml} / \mathrm{kg}$ hemorrhage elicited a significant increase in plasma ACTH on both day 3 and day 6 after surgery (solid symbols). However, the
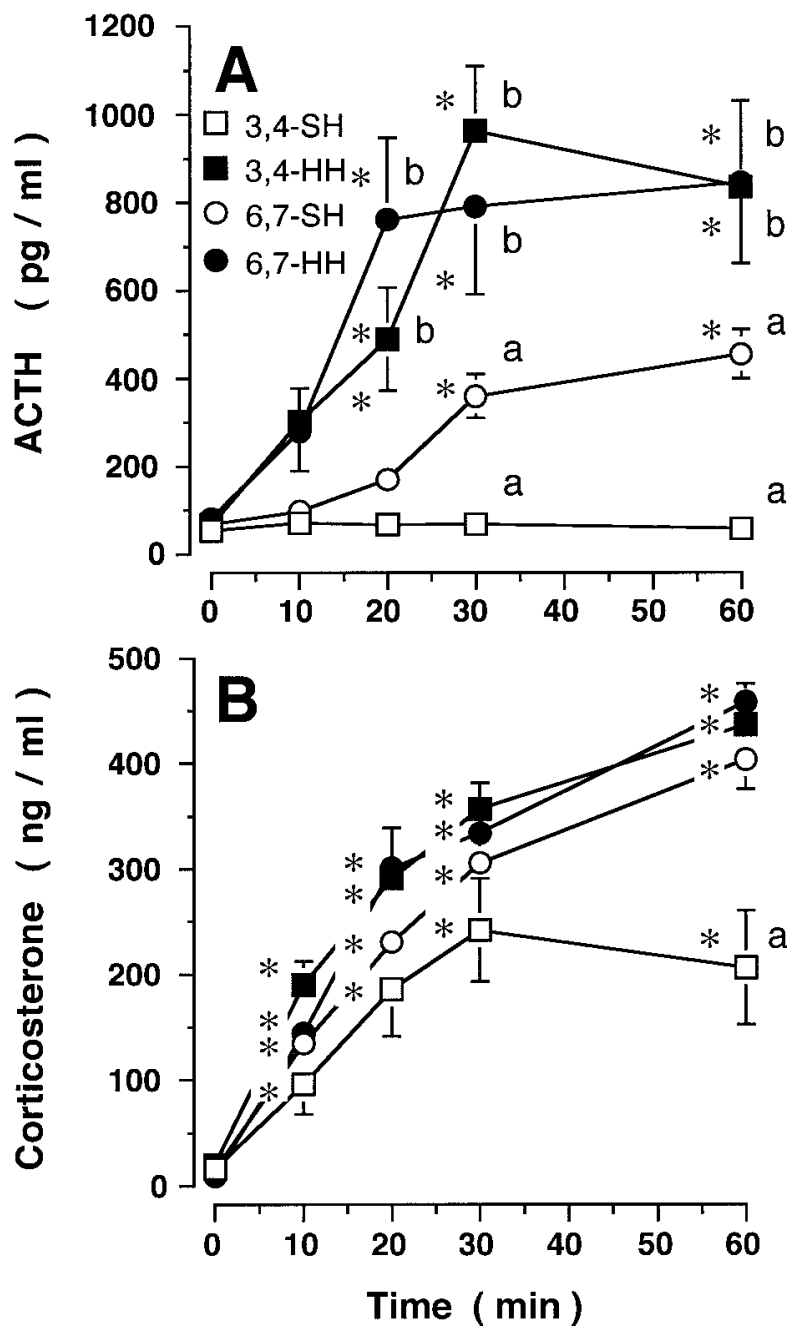

Figure 5 Responses of arterial $\mathrm{ACTH}(\mathrm{A})$ and arterial corticosterone (B) on the second day of experiment 2. A first hemorrhage $(3,4-\mathrm{SH}$ or $6,7-\mathrm{SH})$ or second hemorrhage $(3,4-\mathrm{HH}$ or $6,7-\mathrm{HH}$ ) of $10 \mathrm{ml} / \mathrm{kg}$ was done on either day 4 or day 7 after surgery. Symbols indicate statistical significance as in Fig. 4.

response on day 3 (solid squares) was significantly greater $(P<0 \cdot 01)$ than it was on day 6 (solid circles). Baseline ACTH at time 0 did not differ between groups. ACTH did not increase significantly on either day in response to sampling alone (open symbols). As shown in Fig. 4B, hemorrhage elicited a significant increase in plasma corticosterone $(P<0 \cdot 01)$ on both day 3 and day 6 after surgery. Unlike the responses of the ACTH, the responses of corticosterone to hemorrhage did not differ significantly. Baseline corticosterone did not differ between groups. However, there was a significant increase in the group subjected to sampling alone on day $6(P<0 \cdot 01)$. This response differed from $(P<0 \cdot 01)$ and was about half that measured after hemorrhage (Fig. 4B). 


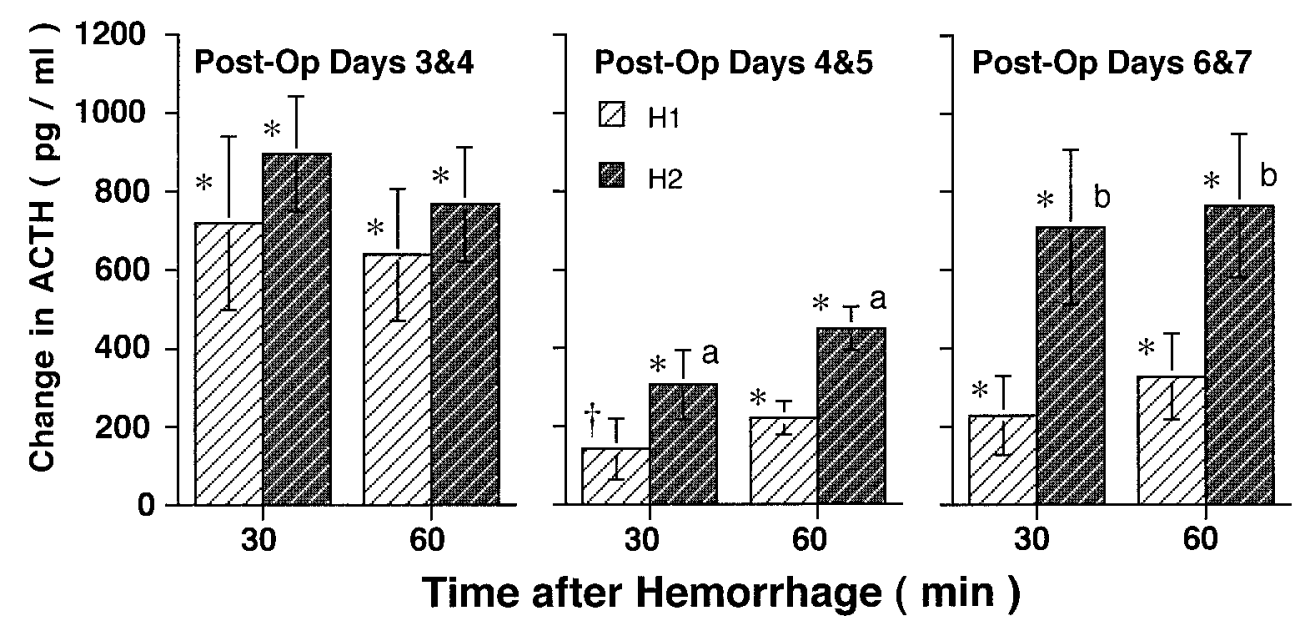

Figure 6 Responses of arterial ACTH at 30 and 60 min after hemorrhage from all groups that received both an initial hemorrhage $(\mathrm{H} 1)$ and a second hemorrhage $(\mathrm{H} 2)$ in experiments 1 and $2 .{ }^{*} P<0.01$ and ${ }^{\dagger} P<0 \cdot 05$, different from $0 .{ }^{\mathrm{a}} \mathrm{P}<0 \cdot 05$ and ${ }^{\mathrm{b}} \mathrm{P}<0 \cdot 01$, different from $\mathrm{H} 1$ at time of observation.

Second day As shown in Fig. 5A, the responses of ACTH to the second of two hemorrhages on days 4 and 7 after surgery (solid symbols) did not differ and were significantly greater $(P<0 \cdot 01$, in each case) than responses to a first hemorrhage that followed sampling alone on the first experimental day (open symbols). The response of ACTH to a first hemorrhage on day 4 (open squares) was significantly less $(P<0 \cdot 01)$ than it was to a first hemorrhage on day 7 (open circles). Baseline ACTH at time 0 did not differ between groups. As shown in Fig. 5B, the responses of corticosterone to hemorrhage in all groups did not differ significantly for the first $30 \mathrm{~min}$. At $60 \mathrm{~min}$ after hemorrhage, corticosterone after a first hemorrhage on day 4 was significantly less $(P<0 \cdot 01)$ than it was in all of the remaining groups.

Although mean arterial pressure decreased significantly from baseline at 20 and $30 \mathrm{~min}$ after a second hemorrhage on day $4(3,4-\mathrm{HH})$, no other significant changes in pressure were observed in the remaining groups (Table 2), and there was no overall difference in mean arterial pressure between groups by ANOVA $(P>0 \cdot 4)$. At 4 days after surgery, heart rate decreased so that its value at 20 min after a first hemorrhage $(3,4-\mathrm{SH})$ and at 10 and 20 min after a second hemorrhage $(3,4-\mathrm{HH})$ was significantly less $(P<0 \cdot 05)$ than the corresponding rates observed on day $7(6,7-\mathrm{SH}$ and $6,7-\mathrm{HH}$; Table 2$)$. In contrast, heart rate increased after a first hemorrhage on day $7(6,7-\mathrm{SH})$ so that its value at 30 min was significantly greater than in the remaining groups $(P<0 \cdot 05)$. Despite these differences between groups at various times after hemorrhage, no group had a significant change in heart rate from its baseline value before hemorrhage.

The responses for all rats that were hemorrhaged twice in the AM in experiments 1 and 2 are summarized in Fig. 6. The response of ACTH to a second hemorrhage on either day 5 or day 7 after surgery exceeded that to the first hemorrhage on the previous day $(P<0 \cdot 05)$, whereas the responses to the sequential hemorrhages on days 3 and 4 did not differ.

\section{Discussion}

These experiments were designed to identify conditions under which an initial episode of hypovolemia would enhance the response of ACTH to a hemorrhage repeated $24 \mathrm{~h}$ later in rats. Potentiated responses of the HPA system to repeated hemorrhage are known to involve changes both in ACTH responses and in adrenal sensitivity to ACTH (Lilly et al. 1983, 1986, 1989, Thrivikraman et al. 1993, Lilly 1994). An experimental model of this potentiation would allow physiological exploration of the interplay of the central neural and peripheral factors that underlie this phenomenon. In fact, we have recently used this model to demonstrate the necessity of neuronal processing in the caudal amygdala for potentiated ACTH responses to repeated hemorrhage (Lilly et al. 2000). In developing this model, we have investigated the role of circadian rhythm and preparative surgery in the responses of the HPA to hemorrhage. It is clear from our data that enhanced responses of ACTH to hemorrhage are best demonstrated in rats that are in a truly resting state. Increases in HPA responsiveness associated either with the time-of-day or with surgical stress may mask potentiated responses to other stimuli such as hemorrhage.

Surgery has been shown to attenuate the amplitude of the circadian rhythm of heart rate and temperature for up to 12 days (Harper et al. 1996). This effect is similar to that in experimental models of chronic stress in the rat (Tannenbaum et al. 1997) that show increased resting 
values of corticosterone in the AM with a reduction in the circadian variation of the hormone. Although corticosterone was not measured in the PM in experiment 1 , a diurnal rhythm in plasma ACTH was evident by 4 days after surgery. This finding is in agreement with the report of Fagin et al. (1983) which demonstrated return of circadian variation of circulating corticosterone in rats 3-6 days after chronic peripheral arterial cannulation. These and other investigators have presented evidence that the basal diurnal rhythm of the HPA must be reestablished after experimental preparation in order to observe normal stress responses (Fagin et al. 1983, Dallman et al. 1987, Nicholson et al. 1987). The presence of the rhythm of ACTH in experiment 1 suggests that the stressful effects of preparative surgery had diminished substantially after 4 days of recovery.

In experiment 1 the responses to the first hemorrhage indicated that the sensitivity of the pituitary to hemorrhage was greatest in the PM near the circadian peak and least in the AM near the nadir of the rat's circadian cycle (Fig. 1). This finding contrasts with data in several other studies which have demonstrated greater ACTH responses in rats to restraint stress in the AM compared to the PM (Kant et al. 1986, Akana et al. 1992, Leal et al. 1995). Several explanations for this divergence are possible. First, the two stimuli have markedly different characteristics. Restraint stress is primarily a psychological stressor, although nociceptive stimuli may also be a component in some models. The hemodynamic effect of restraint is systemic arterial hypertension and tachycardia (Bhatnagar et al. 1998). Hemorrhage as employed in our experiments is primarily a hemodynamic stimulus with no observable evidence of pain or behavioral effects. Hemorrhage in rats of the magnitude employed in our experiments produces brief and modest arterial hypotension and variable heart rate responses (Darlington et al. 1986). It is clear, however, that emotional or psychological inputs can modify both basal and post-stimulus responses of the HPA. For example, the amygdala has long been recognized to exert facilitatory effects on HPA responses (Allen \& Allen 1974, 1975, Feldman \& Conforti 1981, Prewitt \& Herman 1997, Lilly et al. 2000). Although the rats displayed no discernable differences in behavior during either the sampling or hemorrhage protocols (in fact, most animals appeared to sleep during the experiment), fear or other emotional or psychological effects of the protocol cannot be excluded absolutely (Aggleton 1993, Davis 1997). We have attempted to limit the impact of such factors by keeping handling of the animals to a minimum and through the use of sampling controls.

An alternative explanation for the contrasting patterns of pituitary responsiveness to restraint and hemorrhage could be an effect of the stimulus on food intake. For example, Zylan \& Brown (1996) have demonstrated decreased intake of solid food by rats in the $2 \mathrm{~h}$ following a brief period of restraint. Eating is an important cue to entrain circadian rhythms and stress may effect food intake and thereby HPA responsiveness (Dallman et al. 1993). Furthermore, Darlington et al. (1995) have shown significantly reduced blood volume restitution in rats fasted for $24 \mathrm{~h}$ before a large hypotensive hemorrhage $(20 \mathrm{ml} / \mathrm{kg})$. This latter effect appeared to be due to reduced shifts of gastrointestinal fluid into the extracellular compartment. Thus, a major change in food intake could increase the physiological impact of an identical volume hemorrhage, or could modify the HPA responses to this stimulus. Both experiments in this report were designed to limit the effects of these potentially confounding factors on our results. Food and water intake was not measured in either experiment. Food was not withdrawn at any time in the entire post-operative period. Water was withheld only during the hour of the actual experimental protocol each day. Since rats eat and drink primarily (but not exclusively) during the period of activity after lights out and since the hemorrhage (or sampling) was a limited relatively brief stimulus, we assume the rats ate and drank normally. The decreased food and water consumption expected during the lights-on period could have produced mild relative hypovolemia in the PM group of experiment 1, and thus have contributed to the greater ACTH responses in this group. In experiment 2 , all hemorrhages were performed shortly after lights on and were concluded by $90 \mathrm{~min}$ later. Thus, the rats in this protocol had at least $8 \mathrm{~h}$ of lights-on period to recover from any lasting effects of hemorrhage or sampling before beginning the active period prior to the test hemorrhage on the following day.

The pattern of ACTH release following hemorrhage in experiment 1 was different in the AM and PM. AM responses to both hemorrhages were characterized by gradual progressive increases reaching an observed maximum at $60 \mathrm{~min}$. In contrast, PM responses to both hemorrhages showed a peak response at 20-30 min with a decline at $60 \mathrm{~min}$. Although corticosterone was not measured in the PM groups, the enhanced adrenal sensitivity to ACTH at the peak of the circadian cycle would be expected to result in greater increases in circulating corticosterone after hemorrhage in the PM compared to the AM (Dallman et al. 1987). A greater corticosterone feedback signal in the PM could have accounted for the different ACTH response patterns in the two groups. Despite the differences in response patterns, the absolute magnitudes of the responses of ACTH to $10 \mathrm{ml} / \mathrm{kg}$ hemorrhage were similar on both days in the PM and on the second day in the AM. This observation suggests that ACTH responses in this range represent maximal responses to this level of hemorrhage. If this is so, the AM experiment shows facilitation of ACTH responses because the modest magnitude of the hemorrhagic stimulus and the experimental conditions (nadir of the circadian cycle) produce a moderate initial response permitting demonstration of a larger response to the second stimulus. Thus, potentitated ACTH responses may have been 
demonstrated in the PM had a smaller stimulus been employed.

The findings of experiment 1 do not exclude the possibility that the enhanced responses of ACTH to the second hemorrhage were the result of other factors such as differences in the hemodynamic stimulus, lasting effects of preparative surgery, or other uncontrolled stimuli. The hypotension after the second hemorrhage in experiment 1 was not significantly greater than that after the first hemorrhage, and the potentiation of ACTH response did not correlate significantly with added hypotension after the second hemorrhage compared to the first. However, the trends in these relationships were such that the increase in the hypotension from the first to the second hemorrhage may have contributed to an enhanced response of ACTH. One rat in the AM group was a clear exception to this possibility. Hypotension in this rat averaged $10 \mathrm{mmHg}$ after the first hemorrhage and $3 \mathrm{mmHg}$ after the second hemorrhage. By $60 \mathrm{~min}$, plasma ACTH in this rat was $240 \mathrm{pg} / \mathrm{ml}$ after the first hemorrhage and $568 \mathrm{pg} / \mathrm{ml}$ after the second hemorrhage. Thus, greater hypotension was not necessary for a potentiated ACTH response.

A residual deficit in blood volume after the first hemorrhage in some rats may have produced a greater hemodynamic impact of the second isovolemic hemorrhage. Such a deficit was unlikely because the blood reinfused from the first hemorrhage was supplemented with saline, and the rats had free access to food and water between the repeated stimuli. Expansion of the extracellular space by saline infusion has been shown to promote complete restitution of blood volume in dogs within 24 h after moderate hemorrhage (Pirkle \& Gann 1976). Furthermore, Darlington et al. (1995) have shown that chronically cannulated rats similar to those in our experiments will restore their blood volume completely after a large hemorrhage $(20 \mathrm{ml} / \mathrm{kg})$ without any resuscitation.

Greater hypotension after the second hemorrhage might also reflect the additional time for recovery from the preparative surgery on the second day of the experiment. This possibility would result if surgery facilitated the various reflexes that defend the arterial pressure and if the magnitude of this effect declined from the first to the second hemorrhage. Surgery enhances the responsiveness of the HPA system to a variety of stimuli including hemorrhage and hypoxia (Lilly \& Gann 1982, Raff et al. 1983, Lilly 1994), but the exact duration and time-course for recovery of this effect are not known. To address this issue further, experiment 2 included repeated hemorrhages in the early (days 3,4) and late (days 6,7) periods after surgery. Experiments were not done after 7 days because of a greater incidence of catheter thrombosis at this time.

Finally, uncontrolled stimuli such as environmental cues on the two days of experiment 1 may have contributed to our observations. Such stimuli might account for the modest elevation of basal corticosterone in the AM group. To control for these effects and for effects related to the recovery from surgery, experiment 2 included control groups $(3,4-\mathrm{SH}$ and $6,7-\mathrm{SH})$ that received their first hemorrhage on the second day of the experiment after they were subjected to sampling alone on the first day. In addition, we confined our analysis to the rats in experiment 2 with lowest values of plasma corticosterone.

The results from the first day of experiment 2 showed a clear decline in the response of ACTH to a first hemorrhage from post-surgical day 3 to day 6 (Fig. 4A). This finding is similar to our previous observation in chronically prepared dogs that the pituitary-adrenal response to hemorrhage (Lilly 1994) and the adrenocortical sensitivity to ACTH are enhanced on post-surgical day 2 compared to day 5 (Lilly \& Gann 1982).

Both experiments 1 and 2 provide information on the responsiveness of the HPA system to an initial hemorrhage on day 4 after surgery. In experiment 1 , the response of ACTH to the first hemorrhage in the AM of day 4 was modest and significantly less at $30 \mathrm{~min}$ than the responses to the first hemorrhage on either day 3 or day 7 in experiment $2(P<0 \cdot 05$, in each case, see Fig. 6). In experiment 2 , the group with its first hemorrhage on day 4 (3,4-SH) had responses of ACTH and corticosterone that were less than those to the first hemorrhages in any other group. The reason for these modest responses may relate to body weight since the rats in this group $(3,4-\mathrm{SH})$ were significantly heavier than those in the other groups of experiment 2. However, the hemorrhage volume per $\mathrm{kg}$ of body weight of this group did not differ from the remaining groups, and its actual hemorrhage volume was significantly larger in proportion to its greater weight. Growth in adult inbred rats involves the accumulation of fat with little change in their lean body mass. Since blood volume is proportional to lean body mass, the fraction of the total blood volume that was removed by hemorrhage in these heavier rats was likely larger than in the other groups. Thus, $10 \mathrm{ml} / \mathrm{kg}$ hemorrhage in the heavier rats is probably at least as effective a stimulus as the hemorrhages done in the remaining groups. The smaller hormonal response to an initial hemorrhage on day 4 after surgery in experiment 2 compared to experiment 1 (compare Figs 1A and $4 \mathrm{~A}$ ) is most likely related to the lower basal values of corticosterone in experiment $2(16 \cdot 2 \pm 8 \cdot 2 \mathrm{ng} / \mathrm{ml}$ in $3,4-\mathrm{SH}$ group vs $50.5 \pm 17.9 \mathrm{ng} / \mathrm{ml}$ in the day $4 \mathrm{AM}$ group) given our analysis of data from rats that were excluded from this latter experiment. In addition, the day 4 hemorrhage was the first experimental manipulation in the day 4 AM group of experiment 1, whereas that hemorrhage was preceded by sampling in the 3,4-SH group of experiment 2 . These considerations suggest that the animals in experiment 1 may have had some degree of pre-stimulation not present in experiment 2 , and emphasize the value of the controls provided in experiment 2 . 
Taken together, our results clearly indicate that the responsiveness of the HPA system to $10 \mathrm{ml} / \mathrm{kg}$ hemorrhage is elevated in the early period after surgery. The modest response of ACTH to hemorrhage in the AM of day 4 in the presence of a circadian rhythm suggests that the potentiating effects of surgery on the HPA system resolve for the most part after 4-6 days of recovery. In more recent experiments (Lilly et al. 2000), we have continued to observe modest responses of ACTH to this magnitude of an initial hemorrhage on day 4 after surgery.

On the second day of experiment 2, facilitation of the HPA system by prior hemorrhage was evident on both days 4 and 7 after surgery since the control groups that received sampling alone on days 3 and 4 had responses of ACTH that were significantly less than the groups that were hemorrhaged twice (Fig. 4A). Only hypovolemia of about $10 \mathrm{ml} / \mathrm{kg}$ on the first experimental day (but not environmental cues or the smaller amount of hypovolemia due to the sampling) led to an augmented response to hemorrhage $24 \mathrm{~h}$ later. A previous study in chronically prepared rats by Thrivikraman \& Plotsky (1993) showed a modest increase in the response to a second hemorrhage of $14 \mathrm{ml} / \mathrm{kg}$ from that to an initial hemorrhage of equal volume done $90 \mathrm{~min}$ earlier. Their experiments were done on day 4 or 5 after surgery and one or more days after the rats were relocated into new cages. Although the increase in the response to the second hemorrhage seen by these investigators may have been limited by negative feedback from the response of corticosterone after the first hemorrhage, it is also possible that facilitation of the HPA system by the rats' surgery and subsequent relocation reduced the augmentation of the response to the second hemorrhage by the earlier hemorrhage. A similar situation is clearly demonstrated in the group that was hemorrhaged on both days 3 and 4 in experiment 2. By day 6 the response of ACTH to a first hemorrhage had declined significantly from that observed on day 3 , whereas the responses to the second hemorrhage on days 4 and 7 did not differ (Fig. 6).

Potentiation of the response of corticosterone by a prior hemorrhage was only evident when the second hemorrhage was done on day 4 in experiment 2 (Fig. 5B, compare closed and open squares). In all of the remaining cases, the responses of corticosterone to hemorrhage were nearly maximal suggesting that the associated responses of ACTH are sufficient for maximal activation of the adrenal cortex. Increases in ACTH above those required to produce maximal adrenal secretion of corticosterone produce similar peak values of circulating corticosterone, but more prolonged responses of this hormone (Keller-Wood \& Dallman 1984). Because blood was sampled until only 60 min after hemorrhage and values of circulating corticosterone were still elevated relative to basal values, differences in corticosterone responses in the later period after hemorrhage would have been missed by our sampling paradigm. Thus, a more prolonged period of blood sampling and data analysis by integrated corticosteroid concentration (area under the curve analysis) may have demonstrated differences in corticosterone responses that could parallel those of ACTH.

The similar responses of corticosterone in our data may also be the result of differences in the sensitivity of the adrenal cortex to circulating ACTH. We have demonstrated increased adrenal sensitivity to ACTH in dogs prepared for direct measurement of adrenal corticosteroid secretion after either hemorrhage (Lilly et al. 1983, 1986) or surgery (Lilly \& Gann 1982). There is evidence in rats that this effect of surgery may be mediated by modulation of ultradian rhythms in splanchnic nerve activity (Jasper \& Engeland 1994). This effect may account for the significant increase in corticosterone after the non-significant change in ACTH (from $54 \cdot 3 \pm 4 \cdot 4 \mathrm{pg} / \mathrm{ml}$ to a peak of $71 \cdot 1 \pm 13.4 \mathrm{pg} / \mathrm{ml}$ ) in the rats in the $3,4-\mathrm{SH}$ group hemorrhaged first on day 4 in experiment 2 (Fig. 5, open squares). Increased adrenal sensitivity to ACTH may also have contributed to the robust responses of corticosterone to sampling and to hemorrhage in the 6,7-SH group in experiment 2 (Fig. 4 and 5, open circles). Taken together these results suggest that in this model the adrenal sensitivity to ACTH remains high even as the ACTH responses diminish during the first week after surgery. The actual extent to which changes in adrenal sensitivity contributed to our observations is not known since the rates of adrenocortical secretion were not measured. Our findings do indicate that, for this magnitude of hemorrhage, the effect of prior hemorrhage on the responsiveness of the system is best judged from the measurements of plasma ACTH. Had corticosterone alone been measured in these experiments, the dynamics of the HPA responses to hemorrhage may not have been detected.

As in experiment 1 , mild hypotension after the second hemorrhage occurred in the early period after surgery in experiment 2 (group 3,4-HH in Table 2). However, arterial pressure before and after hemorrhage in all groups of experiment 2 did not differ significantly, and the responses of arterial pressure to $10 \mathrm{ml} / \mathrm{kg}$ hemorrhage on day 7 after surgery (groups 6,7-SH and 6,7-HH in Table 2) were nearly identical indicating no effect of prior hemorrhage on the hypotensive response at this later time. Mean arterial pressure was not recorded in the immediate period after hemorrhage in experiment 2 , so that differing degrees of early transient hypotension could have contributed to the augmented response of ACTH to the second hemorrhage. However, the hemodynamic data from experiment 1 show that mean arterial pressure from 10 through $30 \mathrm{~min}$ after hemorrhage matched that at 3 min (Fig. 2). Thus, it is unlikely that significant transient hypotension was overlooked in experiment 2. Similarly, there are no significant differences between the responses of heart rate between the first and second hemorrhages except for the greater heart rate at $30 \mathrm{~min}$ in the group that received its first hemorrhage on day 7 after surgery (Table 2). However, the significantly greater values of 
ACTH after a second hemorrhage compared to a first hemorrhage on day 7 occurred at 10 and 20 min before this difference in heart rate (Fig. 5). Accordingly, none of the observed hemodynamic differences related strongly to the observed potentiation of ACTH release. Thus, the design of experiment 2 applied 6 days after surgical preparation provides for resolution of the facilitatory effects of surgery and eliminates the hemodynamic discrepancies seen after hemorrhage at earlier time points.

In summary, our data show that potentiated ACTH responses to a repeated acute hemodynamic stimulus can be demonstrated in conscious intact rats, but that particular care in experimental design and conduct are required. The interplay of stimulus intensity and time-of-day is shown clearly in experiment 1 where a modest hemodynamic stimulus produced a moderate response in the AM, but a maximal response in the PM. The complex effects of anesthesia and surgery are evident in the distribution of resting corticosterone values 3 and 6 days after surgery, and in the markedly different responses to initial and second hemorrhage in experiment 2. Although potentiated responses of ACTH were demonstrated in both time periods after surgery, this potentiation was evident only in comparison to an initial sham control in the early post-operative period. In contrast, in the later period after surgery potentiated ACTH responses were seen within individual rats (6,7-HH group). Our data fit in well with the evidence of others that facilitation of the pituitary responses (ACTH) to repeated acute stimuli can only be demonstrated in rats in experimental situations with minimal feedback (Akana et al. 1992, Andrés et al. 1999). These observations support the view that type II corticosteroid receptors play a principal role in feedback inhibition of facilitated responses to repeated acute stimuli (Reul \& De Kloet 1985, Dallman et al. 1987, De Kloet et al. 1990, 1993, 1998) and that the threshold for this effect is relatively low. Our results indicate that with a small stimulus and resting subjects these feedback effects can be minimized and facilitation directly demonstrated in rats.

\section{Acknowledgements}

The authors thank Daniel N Darlington for his invaluable assistance in the initial phases of this work and his continued support throughout the project. This work was supported in part by National Institute of Diabetes and Digestive and Kidney Diseases Grant DK 02181 (Clinical Investigator Award, M P L). Portions of this material were presented at the 76th Annual Meeting of the Endocrine Society in Anaheim, CA, USA, June 1994.

\section{References}

Aggleton JP 1993 The contribution of the amygdala to normal and abnormal emotional states. Trends in Neuroscience 16 328-333.
Akana SF, Dallman MF, Bradbury MJ, Scribner KA, Strack AM \& Walker CD 1992 Feedback and facilitation in the adrenocortical system: unmasking facilitation by partial inhibition of the glucocorticoid response to prior stress. Endocrinology 131 57-68.

Allen JP \& Allen CF 1974 Role of the amygdaloid complexes in the stress-induced release of ACTH in the rat. Neuroendocrinology 15 220-230.

Allen JP \& Allen CF 1975 Amygdalar participation in tonic ACTH secretion in the rat. Neuroendocrinology 19 115-125.

Andrés R, Martí O \& Armario A 1999 Direct evidence of acute stress-induced facilitation of ACTH response to subsequent stress in rats. American Journal of Physiology 277 R863-R868.

Bhatnagar S, Dallman MF, Roderick RE, Basbaum AI \& Taylor BK 1998 The effects of prior chronic stress on cardiovascular responses to acute restraint and formalin injection. Brain Research $\mathbf{7 9 7}$ 313-320.

Carlson DE, DeMaria EJ, Campbell RW \& Gann DS 1989 Behavioral and hormonal influence on blood volume restitution after hemorrhage in swine. American Journal of Physiology 256 R207-R216.

Dallman MF \& Jones MT 1973 Corticosteroid feedback control of ACTH secretion: effect of stress-induced corticosterone secretion on subsequent stress responses in the rat. Endocrinology 92 1367-1375.

Dallman MF \& Yates FE 1968 Anatomic and functional mapping of central neural input and feedback pathways of the adrenocortical system. Memoirs of the Society for Endocrinology (London) 17 39-77.

Dallman MF, Akana SF, Cascio CS, Darlington DN, Jacobson L \& Levin N 1987 Regulation of ACTH secretion: variations on a theme of B. Recent Progress in Hormone Research 43 113-173.

Dallman MF, Strack AM, Akana SF, Bradbury MJ, Hanson ES, Scribner KA \& Smith M 1993 Feast and famine: critical role of glucocorticoids with insulin in daily energy flow. Frontiers in Neuroendocrinology 14 303-347.

Darlington DN, Shinsako J \& Dallman MF 1986 Responses of ACTH, epinephrine, norepinephrine, and cardiovascular system to hemorrhage. American Journal of Physiology 251 H612-H618.

Darlington DN, Jones RO, Magnuson TA \& Gann DS 1995 Role of intestinal fluid in restitution of blood volume and plasma protein after hemorrhage in awake rats. American Journal of Physiology 268 R715-R722.

Davis M 1997 Neurobiology of fear responses: the role of the amygdala. Journal of Neuropsychiatry and Clinical Neurosciences $\mathbf{9}$ 382-402.

De Kloet ER, Reul JMHM \& Sutanto W 1990 Corticosteroids and the brain. Journal of Steroid Biochemistry and Molecular Biology 37 387-394.

De Kloet ER, Oitzl MS \& Joels M 1993 Functional implications of brain corticosteroid receptor diversity. Cellular and Molecular Neurobiology 13 433-455.

De Kloet ER, Vreugdenhil E, Oitzl MS \& Joels M 1998 Brain corticosteroid receptor balance in health and disease. Endocrine Reviews 19 269-301.

Fagin KD, Shinsako J \& Dallman MF 1983 Effects of housing and chronic cannulation on plasma ACTH and corticosterone in the rat. American Journal of Physiology 245 E515-E520.

Feldman S \& Conforti N 1981 Amygdalectomy inhibits adrenocortical responses to somatosensory and olfactory stimulation. Neuroendocrinology 32 330-334.

Gann DS \& Cryer GL 1973 Feedback control of ACTH secretion by cortisol. In Brain-Pituitary-Adrenal Interrelationships, pp 197-223. Eds A Brodish \& ES Redgate. Basel, Switzerland: Karger.

Gann DS, Cryer GL \& Pirkle JC Jr 1977 Physiological inhibition and facilitation of adrenocortical response to hemorrhage. American Journal of Physiology 232 R5-R9.

Harper DG, Tornatzky W \& Miczek KA 1996 Stress induced disorganization of circadian and ultradian rhythms: comparisons of effects of surgery and social stress. Physiology and Behavior 59 409-419. 
Jasper MS \& Engeland WC 1994 Splanchnic neural activity modulates ultradian and circadian rhythms in adrenocortical secretion in awake rats. Neuroendocrinology 59 97-109.

Kant GJ, Mougey EH \& Meyerhoff JL 1986 Diurnal variation in neuroendocrine response to stress in rats: plasma ACTH, $\beta$-endorphin, $\beta$-LPH, corticosterone, prolactin and pituitary cyclic AMP responses. Neuroendocrinology 43 383-390.

Keller-Wood ME \& Dallman MF 1984 Corticosteroid inhibition of ACTH secretion. Endocrine Reviews 5 1-24.

Leal AMO, Forsling ML \& Moreira AC 1995 Diurnal variation of the pituitary-adrenal and AVP responses to stress in rats under food restriction. Life Sciences 56 191-198.

Lilly MP 1994 Effect of surgery on the pituitary-adrenal response to repeated hemorrhage. American Journal of Physiology 266 R1976-R1984.

Lilly MP \& Gann DS 1982 The effect of repeated surgery on the response of the adrenal cortex to infused ACTH. Surgical Forum 33 $10-12$.

Lilly MP, Engeland WC \& Gann DS 1983 Responses of cortisol secretion to repeated hemorrhage in the anesthetized dog. Endocrinology 112 681-688.

Lilly MP, Engeland WC \& Gann DS 1986 Pituitary-adrenal responses to repeated small hemorrhage in conscious dogs. American Journal of Physiology 251 R1200-R1207.

Lilly MP, DeMaria EJ, Bruhn TO \& Gann DS 1989 Potentiated cortisol response to paired hemorrhage: role of angiotensin and vasopressin. American Journal of Physiology 257 R118-R126.

Lilly MP, Putney DJ \& Carlson DE 2000 Potentiated response of ACTH to repeated moderate hemorrhage requires amygdalar neuronal processing. Neuroendocrinology 71 88-98.

Nicholson SA, Campbell EA, Gillham B \& Jones MT 1987 Recovery of the components of the hypothalamo-pituitary-adrenocortical axis in the rat after chronic treatment with prednisolone. Journal of Endocrinology 113 239-247.

Pirkle JC Jr \& Gann DS 1976 Restitution of blood volume after hemorrhage: role of adrenal cortex. American Journal of Physiology $2301683-1687$.
Plotsky PM, Thrivikraman KV \& Meaney MJ 1993 Central and feedback regulation of hypothalamic corticotropin-releasing factor secretion. In Corticotropin-Releasing Factor (Ciba Foundation Symposium 172), pp 59-84. Eds D J Chadwick, J Marsh \& K Ackrill. Chichester: John Wiley.

Prewitt CM \& Herman JP 1997 Hypothalamo-pituitaryadrenocortical regulation following lesions of the central nucleus of the amygdala. Stress 1 263-280.

Raff H \& Fagin KD 1984 Measurement of hormones and blood gases during hypoxia in conscious cannulated rats. Journal of Applied Physiology 56 1426-1431.

Raff H, Shinsako J \& Dallman MF 1983 Surgery potentiates adrenocortical responses to hypoxia in dogs. Proceedings of the Society for Experimental Biology and Medicine 172 400-406.

Reul JMHM \& De Kloet ER 1985 Two receptor systems for corticosterone in rat brain: microdistribution and differential occupation. Endocrinology 117 2505-2511.

Tannenbaum BM, Brindley DN, Tannenbaum GS, Dallman MF, McArthur MD \& Meaney MJ 1997 High-fat feeding alters both basal and stress-induced hypothalamic-pituitary-adrenal activity in the rat. American Journal of Physiology 273 E1168-E1177.

Thrivikraman KV \& Plotsky PM 1993 Absence of glucocorticoid negative feedback to moderate hemorrhage in conscious rats. American Journal of Physiology 264 E497-E503.

Thrivikraman KV, Plotsky PM \& Gann DS 1993 Alterations of locus coeruleus noradrenergic activity in relation to pituitary secretion after hemorrhage in cats. Neuroscience Letters $16185-88$.

Winer BJ, Brown DR \& Michels KM 1991 Statistical Principles in Experimental Design. New York: McGraw-Hill.

Zylan KD \& Brown SD 1996 Effect of stress and food variety on food intake in male and female rats. Physiology and Behavior 59 165-169.

Received 14 January 2000

Revised manuscript received 13 July 2000

Accepted 26 July 2000 